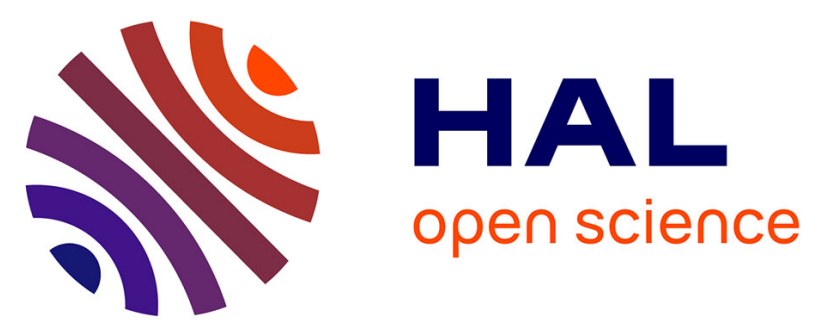

\title{
Knowledge and opinions of French dental students related to caries risk assessment and dental sealants (preventive and therapeutic)
}

Justine Le Clerc, Marie-Agnès Gasqui, Laurent Laforest, Maxime Beaurain, Romain Ceinos, Florence Chemla, Valérie Chevalier, Pierre Colon, Florence Fioretti, Alexis Gevrey, et al.

\section{To cite this version:}

Justine Le Clerc, Marie-Agnès Gasqui, Laurent Laforest, Maxime Beaurain, Romain Ceinos, et al.. Knowledge and opinions of French dental students related to caries risk assessment and dental sealants (preventive and therapeutic). Odontology, 2021, 109 (1), pp.41-52. 10.1007/s10266-020-00527-7 . hal-02862238

\section{HAL Id: hal-02862238 \\ https://hal-univ-rennes1.archives-ouvertes.fr/hal-02862238}

Submitted on 9 Jul 2020

HAL is a multi-disciplinary open access archive for the deposit and dissemination of scientific research documents, whether they are published or not. The documents may come from teaching and research institutions in France or abroad, or from public or private research centers.
L'archive ouverte pluridisciplinaire HAL, est destinée au dépôt et à la diffusion de documents scientifiques de niveau recherche, publiés ou non, émanant des établissements d'enseignement et de recherche français ou étrangers, des laboratoires publics ou privés. 


\section{TITLE PAGE}

Title: Knowledge and opinions of French dental students related to caries risk assessment and dental sealants (preventive and therapeutic)

Authors: Justine Le Clerc ${ }^{1}$, Marie-Agnès Gasqui ${ }^{2}$, Laurent Laforest ${ }^{3}$, Maxime Beaurain ${ }^{4}$, Romain Ceinos ${ }^{5}$, Florence Chemla ${ }^{6}$, Valérie Chevalier ${ }^{7}$, Pierre Colon ${ }^{8}$, Florence Fioretti ${ }^{9}$, Alexis Gevrey ${ }^{10}$, Olivia Kérourédan ${ }^{11}$, Delphine Maret ${ }^{12}$, Caroline Mocquot ${ }^{8}$, Canan Özcan ${ }^{13}$, Bruno Pelissier ${ }^{14}$, Fabienne Pérez ${ }^{15}$, Elodie Terrer ${ }^{16}$, Yann-Loïg Turpin ${ }^{17}$, Reza Arbab-Chirani ${ }^{18}$, Dominique Seux ${ }^{2}$, Sophie Doméjean ${ }^{19}$

\section{Affiliations}

${ }^{1}$ Univ Rennes, CHU Rennes (pôle odontologie), CNRS, ISCR (Institut des Sciences Chimiques de Rennes) - UMR 6226, Rennes, France

${ }^{2}$ UFR d'Odontologie, Laboratoire des Multimatériaux et Interfaces, UMR CNRS 5615, Université Lyon 1, Lyon, France; Hospices Civils de Lyon, Département d'Odontologie Conservatrice, Lyon, France

${ }^{3}$ UFR d'Odontologie, Université Lyon 1, Lyon France

${ }^{4}$ UFR d'odontologie, Lille, France

${ }^{5}$ Université Côte d'Azur, UFR d'odontologie de Nice; Hôpital St Roch, pôle Odontologie, CHU de Nice; UMR 7268, Anthropologie bio-culturelle, Droit Éthique et Santé (ADES), Aix-Marseille Université, France

${ }^{6}$ Faculté de chirurgie dentaire de l'université Paris Descartes; Service de médecine buccodentaire de l'hôpital Charles Foix, APHP Paris, France

${ }^{7}$ UFR d'odontologie de Brest, UBO, Brest ; CHRU de Brest; Institut de Recherche Dupuy de Lome, UMR CNRS 6027, F-29200 Brest, France

${ }^{8}$ Université de Paris, Faculté dentaire, Hôpital Rothschild, Assistance Publique-Hôpitaux de Paris, France. Univ Lyon - Claude Bernard Lyon 1, UMR CNRS 5615, Laboratoire des Multimatériaux et Interfaces, F-69622 Villeurbanne, France

${ }^{9}$ Faculté de Chirurgie Dentaire de l'Université de Strasbourg, Pôle de Médecine et Chirurgie Bucco-dentaires des Hôpitaux Universitaires, UMR INSERM 1260, Strasbourg, France

${ }^{10}$ UFR d'odontologie, Nancy, France

${ }^{11}$ Université de Bordeaux, UFR des Sciences Odontologiques, F-33076 Bordeaux, France; CHU de Bordeaux, Service de Médecine Bucco-dentaire, F-33076 Bordeaux, France; INSERM, Bioingénierie Tissulaire, U1026, F33076 Bordeaux, France

${ }^{12}$ UFR d'odontologie, Toulouse, CHU de Toulouse, Laboratoire AMIS, UMR 5288 CNRS, Toulouse, France

${ }^{13}$ Département d'odontologie conservatrice, Université de Reims Champagne-Ardenne, UFR d'Odontologie, Reims, France

${ }^{14}$ UFR d'odontologie, Montpellier, France

${ }^{15}$ Département d'Odontologie Conservatrice-Endodontie, Univ Nantes, UFR Odontologie \& CHU Nantes, PHU 4 OTONN, 44042 Nantes, France

${ }^{16}$ UFR d'odontologie, Aix-Marseille Univ., IRD, MEPHI, IHU Méditerranée Infection, Marseille, France

${ }^{17}$ Univ Rennes, CHU Rennes (pôle odontologie), France 
${ }^{18}$ UFR d'odontologie de Brest, UBO, Brest; CHRU de Brest; LaTIM UMR 1101 INSREM, Brest, France

${ }^{19}$ Département d'OdontologieConservatrice, Univ Clermont Auvergne, UF R d'Odontologie; Centre de Recherche en Odontologie Clinique EA 4847, F-63100 Clermont-Ferrand, France; CHU Estaing Clermont-Ferrand, Service d'Odontologie, F-63001 Clermont-Ferrand, France

\section{Author contributions}

Conceptualization: Sophie Doméjean and Dominique Seux

Methodology: Sophie Doméjean and Dominique Seux

Data collection: Justine Le Clerc, Marie-Agnès Gasqui, Laurent Laforest, Maxime Beaurain, Romain Ceinos, Florence Chemla, Valérie Chevalier, Pierre Colon, Florence Fioretti, Alexis Gevrey, Olivia Kérourédan, Delphine Maret, Caroline Mocquot, Canan Özcan, Bruno Pelissier, Fabienne Pérez, Elodie Terrer, Yann-Loïg Turpin, Reza Arbab-Chirani, Dominique Seux, Sophie Doméjean

Data entry: Sophie Doméjean, Dominique Seux and Marie-Agnès Gasqui

Formal analysis: Sophie Doméjean, Dominique Seux and Laurent Laforest

Writing - original draft preparation: Justine Le Clerc

Writing - review and editing: SophieDoméjean, DominiqueSeux, Laurent Laforest, Marie-Agnès Gasqui, Laurent Laforest, Maxime Beaurain, Romain Ceinos, Florence Chemla, Valérie Chevalier, Pierre Colon, Florence Fioretti, Alexis Gevrey, Olivia Kérourédan, Delphine Maret, Caroline Mocquot, Can an Özcan, Bruno Pelissier, Fabienne Pérez, Elodie Terrer, Yann-Loïg Turpin, Reza Arbab-Chirani

Supervision: Sophie Doméjean and Dominique Seux

All authors read and approved the final manuscript.

\section{Corresponding author}

Sophie Doméjean

UFR d'Odontologie

2 rue de Braga, 63100 Clermont-Ferrand, France

E-mail: sophie.domejean@uca.fr

Tel: +33663047143

\section{Abstract}

Objectives: A national questionnaire study was performed to document knowledge and opinions of French dental students (FDSs) about minimal intervention (MI) in dentistry especially caries risk assessment (CRA) and dental sealants (DSs).

Materials and Methods: A questionnaire was administered to the fifth-year dental FDSs $(n=1,370)$ from the 16 French dental schools. Descriptive and statistical analyses were performed.

Results: Theresponse rate was $84.5 \%$. A large majority of respondents $(87.8 \%)$ linked MI with minimally invasive dentistry and $77.4 \%$ considered MI as a concept based on prevention. About $80 \%$ stated they use CRA in clinical practice, mostly without any specific form. If $80.4 \%$ of the respondents would base their treatment plans on CRA, only $55.1 \%$ would regularly plan preventive regimens according to individual risk level. However, while $96.6 \%$ declared they perform preventive DSs, only $44.3 \%$ considered therapeutic sealants as a routinetreatment. Although 
$75.1 \%$ of FDSs stated that they had sufficient learning and training related to CRA, $55.9 \%$ thought that they need further education about preventive and therapeutic DSs.

83 Conclusion: Although FDSs seem to be aware of the importance of CRA and preventive strategies, this study shows the need to harmonize the teaching in cariology according to the latest European recommendations.

Clinical relevance: A national questionnaire study showed variability towards knowledge and opinions ofFDSs related to minimal intervention in cariology. This may impact care provisions in their future professional life showing the urgent need to harmonize the teaching of MI in cariology in France.

\section{Key-words}

- Minimal intervention dentistry

- Caries risk assessment

- Dental sealants

- Dental students

- Questionnaire survey

Acknowledgements: The authors thank Colgate ${ }^{\circledR}$ France for administrative support (printing and postal fees were sponsored by Colgate ${ }^{\circledR}$ France) and Laura Dupont-Butez for her help in data entry. 


\section{Introduction}

Minimal intervention in dentistry (MID) in general and in cariology in particular was first described in the literature with two major articles in the early 1990s $[1,2]$. Indeed, Dawson and Makinson introduced an emerging movement in the late $1980 \mathrm{~s}$ in UK, which denounced the inadequacy between patient needs and care provision in restorative dentistry. In 1992, the foundation $\underline{\underline{s}}$ of MID were thus laid as these two authors suggested that "Prevention", "Remineralization", "Minimal intervention" and "Reducing the rate of restoration placement" could be combined to achieve a less destructive form of dental treatment [2]. Since then, in the light of accumulated knowledge in cariology (histology, microbiology, pathophysiology, validated clinical procedures), this has led to the development of various diagnosis and treatment concepts [3-8]. The latest comprehensive practice guide Caries $\underline{\text { Care International [8] promotes a patient-centered, risk-based approach to caries management designed for dental }}$ practice. It advocates for a health outcomes-focused system that aims to maintain oral health and preserve tooth structure in the long term. In that context, this is obvious that caries risk assessment (CRA) as well as preventive and non-invasive cares (such as dental sealants (DSs)) are essential in caries management.

Questionnaire surveys were conducted in France to assess professional dental practice in terms of minimal intervention (MI) in caries management. In general, studies investigating various domains of caries management (CRA use, DSs placement, restorative threshold for both occlusal and approximal lesion and deep caries management) showed that MI is still insufficiently implemented in everyday clinical practice by French general dental practitioners (FGDPs) practicing in France_[9-13][1-5]. For example, Schwendicke et al show that more than $65 \%$ of the respondents promote complete dentin excavation when selective excavation would have been indicated in deep carious lesions without any sign of pulpal involvement [5]. In the same way, Doméjean et al reported that caries risk assessment (CRA) was not part of their routine practice [4] and that FGDPs would prepare cavities and place restorations for lesions that could benefit from non-invasive strategies [2]. Regarding the use of dental seatants (DSs), even though the majority ofFGDPs (90\%) performed preventive DSs, less than halfof them $(42 \%)$ considered therapeutic DSs as a routine treatment for non-cavitated carious lesions [3]- It is known that ç $\in$ hanging professional practice takes time_[14][6] and is subordinated to a range of factors related to financial considerations (such as remuneration or risk of losing incomes), patients demands and expectations, organizational factors (delegation possibility), GDPs personal attitudes (personal resistance and inertia to change) and, of course, to GDPs education (pre- and post-graduate) [15][7]. It might be speculated that the gap between science and clinical practice described among FGDPs and worldwide [16] could find its origin in dental schools. In that context, the French national [16][16][16][15]college of teachers in conservative dentistry (collège national des enseignants en odontologie conservatrice or CNEOC) started giving thought to what French dental students (FDSs) of the 16 French dental schools know about MI.

A study, which is the first of its kind in France, was thus undertaken to investigate the knowledge and opinions of FDSs at a national level about several areas of MI in cariology, namely CRA, DSs (preventive and therapeutic), restorative threshold and strategies for approximal and occlusal lesions, and deep carious lesion management. The present manuscript focuses on the first two above-mentioned areas i.e. CRA and DSs.

\section{Material and methods}

A questionnaire survey was administered during spring 2018 to the fifth-year FDSs from the 16 French 
dental schools. This project is institutionally supported by the Collège National des Enseignants en Odontologie Conservatrice (CNEOC; French national-association of teachers in conservative dentistry). The printing and postal-mailing costs were sponsored by Colgate $($ France.

\section{Population study and questionnaire administration}

The study involved all fifth-year (penultimate year before graduation) FDSs ( $n=1,370$ in 2018) from the 16 French dental schools (Bordeaux, Brest, Clermont-Ferrand, Lille, Lyon, Marseille, Montpellier, Nancy, Nantes, Nice, Paris Descartes, Paris Diderot, Reims, Rennes, Strasbourg and Toulouse).

A compilation of five questionnaires that had been previously used for surveys among FGDPs and French university teachers $[9-13,17][1-5,8]$ was auto-administrated (paper format -18 pages) to the FDSs in a specific session organized in each of the 16 French dental schools. It consisted of several question formats (yes/no questions, closed-ended questions with forced choice or multiple allowable answers and open-ended questions with open-ended written); five different parts can be identified and can be divided in the following sections:

- Section 1: demographic characteristics of the respondents (birth year and gender); and a question related to the reading of scientific articles about MI in cariology in addition to academic lectures and tutorials;

- Section 2: 13 questions related to CRA [12][4];

- Section 3: 16 questions related to preventive and therapeutic DSs [11][3];

- Section 4: 17 questions related to restorative threshold for approximal and occlusal carious lesions, to two clinical cases of minor or questionable occlusal lesions (based on occlusal views and radiographs) and to beliefs about selected aspects of caries diagnosis / treatment $[9,10,17][1,2,8]$;

- Section 5: 13 questions related to deep carious lesion management (including three clinical cases) [13][5]. The content of the different sections is detailed in the princeps articles $[9-13,17][1-5,8]$.

\section{Capture and analysis of data}

Data were entered into Excel spread sheets by four people (three dentists (MAG, DS, SD) and a Master student (LDB). Descriptive and statistical analyses were performed with SPSS ${ }^{\circledR}$ (IBM SPSS Statistics Version 19). A $\chi 2$ test was used to assess the associations between responses related to, on the one hand, CRA, DSs, restorative threshold/strategies for approximal and occlusal lesions and deep carious lesion management and, on the other hand, gender and additional reading of scientific articles about MI in cariology. Univariate and multivariate logistic regressions (LRs) were performed; odd ratios (ORs) and their $95 \%$ confidence intervals $(95 \% \mathrm{CI})$ were calculated to correlate the use of CRA in everyday practice and the sociodemographic characteristics of the respondents. The level of significance was placed at $5 \%$ for all analyses. Only factors with univariate $\mathrm{p}$-value $<0.20$ were included in the multivariate models.

The present paper only focuses on the results related to sections 1 and 2, namely CRA and preventive and therapeutic DSs. The following subgroups were used for statistical analysis:

- Question on the importance of different factors in treatment planning for adult patients: " not or marginally important" (grade 1) versus "moderately important" (grade 2) versus "very to extremely important" (grade 3);

- Question on the respondents' opinions about general concerns related to preventive and therapeutic DSs: “disagreement (partial or total)" (grade 1) versus " neutral” (grade 2) versus " agreement (partial or total)" (grade 3). 


\section{Results}

All of the 16 French dental schools participated to the survey. A total of 1,158 fulfilled questionnaires were collected, leading to a response rate of $84.5 \%$ (from 32.9 to 100\%). The respondent population was composed of $53.5 \%$ of women $(n=619)$ and $46.5 \%$ of men $(n=539)$. The average age of the participants, at the time of the study, was $24.5( \pm 2.12)$ year-old (min. $21-\max .44)$. Approximately one third of the respondents $(35 \%)$ had already read publications about MI in cariology. Men were more likely to read scientific articles than women $(\mathrm{p}=0.032)$.

\section{CRA}

Interestingly, $81.1 \%$ of respondents stated they use CRA in clinical practice, most of them without any specific form (73.5\%). The reasons for not using CRA are listed in Table 1. Lack of time appears to be the most important factor identified (67.7\%) followed by lack of teaching during undergraduate education $(30.9 \%)$ and insufficient knowledge on CRA (23.5\%). Among those who answered they do not assess the caries risk of their patients, 73.6\% would appreciate the delegation of this task to other dental personnel i.e dental hygienists (69.9\%) or other GDPs (3.7\%), when $12 \%$ would not delegate CRA (14.4\% having no opinion). Men were more likely than women to denounce the problem of billing and reimbursement as barriers to the CRA use ( $\mathrm{p}=0.037)$. Table 2 shows the results of the univariate and multivariate LRs investigating the correlation between the use of CRA and sociodemographic data. The LR shows that respondents who considered initial training on CRA as sufficient were more likely to perform CRA than the others (OR: 2.46; $95 \%$ CI: 1.79-3.37; p-value $<0.001$ ).

If $80.4 \%$ of the respondents would base their individual treatment plans on CRA, only $55.1 \%$ would regularly plan preventive regimens according to risk level. Respondents who are more likely to establish individual preventive strategies based on CRA are MI scientific article readers $(p=0.028)$. Table 3 shows a summary of preventive treatments proposed by respondents: DSs (83.4\%), fluoride (F) varnish application (69\%) and F toothpaste $>1,500 \mathrm{ppm}$ prescription $(41.6 \%)$ were the most cited options. FDSs who already read scientific publications about MI were more likely to indicate $>1,500 \mathrm{ppm} F$ toothpaste $(\mathrm{p}=0.046$ ), CPP/ACP (for casein phosphopeptide - amorphous calcium phosphate) agents $(\mathrm{p}<0.001)$ and $\mathrm{F}$ gel professional application $(\mathrm{p}=0.001)$ than the others. Almost $80 \%(\mathrm{n}=905)$ of the respondents declared combining regularly from two to four preventive options.

Table 4 summarizes the hierarchy of factors being considered in a CRA in adult patients. The three most cited factors considered as important were: current oral hygiene (87.4\%), patient's motivation (45\%) and the presence of active carious lesion (37\%). The three most cited factors considered as irrelevant were: reimbursement (73.7\%), dentist's subjective assessment (53.2\%) and patient's age (31.6\%). Table 5 indicates the results of the uni- and multi-variate LRs performed to investigate the associations between the use of CRA in adults and factors considered as being important. In multivariate analysis, current diet was, by far, the factor with the strongest statistical association with CRA use (OR: 1.80; 95\% CI: 1.25-2.59; p-value: 0.0014). Considering reimbursement and patient's comprehension of the causes were other significantly related factors $(p=0.0393$ and $p=0.0497$, respectively).

Table 6 shows the factors that are considered by FDSs to be important for the treatment plan in adults. The three most cited factors were as follows: current oral hygiene $(95.7 \%)$, patient motivation $(91.9 \%)$ and the regularity of patient visits $(75.6 \%)$. The respondent sociodemographic characteristics appeared to influence their answers. For example, women are more likely to designate the presence of several large restorations, the presence 
of dental appliances, the patient comprehension of the causes of caries and the regularity of patient visits as important factors $(\mathrm{p}=0.045 ; \mathrm{p}=0.005 ; \mathrm{p}<0.001$ and $\mathrm{p}=0.007$, respectively). FDSs who read articles on MI also mentioned the presence of active carious lesion $(p=0.041)$, the current use of $F$ toothpaste $(p=0.001)$ and the current diet $(\mathrm{p}<0.001)$ as main factors in a treatment plan for adults more likely than the others.

\section{Understanding/perception of the term "MI" in cariology}

Table 7 provides an overview of the understanding/perception of the term "MI" in cariology. A large majority of respondents $(87.8 \%)$ linked MI with minimally invasive dentistry while $77.4 \%$ considered it as a concept based on prevention. Women were more likely to answer that MI is based on prevention $(\mathrm{p}=0.013)$ and that MI could be implemented into private practice $(\mathrm{p}<0.001)$. Moreover, $6.4 \%$ reported that they did not exactly know what MI in cariology means.

\section{Preventive and therapeutic DSs}

While $96.6 \%$ of the respondents declared they perform preventive DSs (PDSs), only $44.3 \%$ considered therapeutic DSs (TDSs) as a routine treatment. FDSs who read articles on MI were more likely to perform TDSs $(p<0.001)$ than the others. The lack of formation, the risk of progression of pre-existing carious lesion and the lack of recommendations appeared to be the main reasons for not considering TDSs in their panel of caries management strategies (Figure 1). Table 8 summarizes the respondents' degree of agreement regarding six statements about DSs: $76.4 \%$ considered there are strong evidence on the effectiven ess of DSs to prevent dental caries and $92.4 \%$ were aware that DSs placement implies a follow-up.

Table 9 shows the preferences of the respondents for PDSs and TDSs in terms of patient profile (age and caries risk level) and the choice of material. Composite resin is the preferred material (PDSs: 60.6\%; TDSs: 37\%), especially for respondents who read articles on MI $(\mathrm{p}<0.001)$. Almost $85 \%$ (especially women $\mathrm{p}=0.042$ and respondents who read articles on MI $\mathrm{p}=0.018$ ) combined PDSs with other preventive measures - based on the age of patient (Table 10).

\section{DSs and task delegation}

Almost half of the respondents (48.8\%) would appreciate the possibility of task delegation to other dental personnel. Respondents who read articles on MI were more likely to refuse task delegation $(\mathrm{p}=0.043)$.

\section{National recommendations and need for further education toward CRA and DSs}

Only $26.1 \%$ of the respondents seemed to be familiar with the French national recommendations of the French High Authority for Health (HAS). While 75.1\% stated they had sufficient education towards CRA, 55.9\% reported the need for further education on PDSs and TDSs.

\section{Discussion}

The purpose of this study, the first of its kind in France and in the world, was to provide an overview of the knowledge and opinions of French fifth-year dental students related to CRA and DSs. Studies were previously carried out to assess the teaching of cariology in Europe [18][9] and in Oceania [19][10], but, to our knowledge, no publications were interested in what FDSs, following courses on MI, learn and remember. The logistical part of this study (questionnaire printing and mailing) was supported by Colgate $\Re$, but the results were independently analysed by the authors. As the questionnaire only concerned the learning outcomes, no approval of ethical committees was required according to the French regulation. The 16 French dental schools, all supported by the French State (there are no private dental schools in France), took part in the survey and it can be hypothesized that, 
as the response rate is about $85 \%$, the results are highly representative of the knowledge and opinions of all French fifth-year dental students at the timeof the study. Disparities in response rates between schools could be denounced as a potential bias in the interpretation of the results. Those disparities are related to the fact that, in some schools, the presence of students at the questionnaire administration session was not compulsory. Thus, the non-responses were not linked to the content of the questionnaire and the lack of interest toward MI but only to the irregular school attendance of a fraction of the student population, varying from school to school. In that context, it can be hypothesized that the non-responses do not induce any bias in the interpretation of the results and that the present results are highly representative of the knowledge and practices of FDSs. A comparison between schools was not expected, as the aim of the study was to collectively analyse the knowledge of all future dental French practitioners and not to establish a ranking of schools. Nevertheless, this study does present some limitations. The dental course in France lasts six years and it could have been more pertinent to administrate the questionnaire to final year FDSs as MI in cariology is taught all along the course. Nevertheless, it would have been impossible to simultaneously organise sessions for the questionnaire administration (or within a reasonable period of time to avoid questionnaire diffusion and potential discussions/responses through social networks) to final year FDSs in all schools. Indeed, the presence of the FDSs on site may vary dramatically from one school to another due to an internship (similar to vocational training) in private practice that takes place during this final year. Some authors denounced that there is little correlation between respondents' stated intervention strategies as reported in questionnaire surveys and their therapy decisions in clinical practice [20-22]. Nevertheless, others argued that if questionnaire surveys are not able to measure the respondents' clinical decisions, they give a good idea of their treatment philosophies [23, 24]. The present results thus help to understand FDSs knowledge toward CRA and dental sealants in order to modify teaching content and approaches accordingly.

The questionnaire used in the present survey consisted of a compilation of questionnaires that had been previously used for surveys among FGDPs and French university teachers [9-13, 17]. Validation of the questionnaires was not undertaken since their objective was to describe the knowledge, opinions and practices of dental professionals concerning various MI domains. This differs from questionnaires where the aim is to diagnose a disease, to screen patients according to a specific medical condition or to assess quality of life where validation is necessary. Construct validity of each original questionnaire was, however, evaluated to some extent by pilot-testing the questionnaires like stipulated in the princeps articles [9-13, 17]. Minor problems in the understanding and interpretation of some questions were discussed amongst the investigators and slight modifications to the questionnaire were made. Validation in terms of test-retest reliability of the questionnaire was not evaluated since it was considered that once the questionnaire has been administered, respondents might seek further information about some topics covered in the questionnaire, which, in turn, might subsequently change their opinions and practices. Linguistic validity was not required since the questionnaires were developed in French.

It is comforting to notice that a large majority of FDSs $(81.1 \%)$ stated they regularly conduct CRA, which is recognized to be the cornerstone of MI treatment planning [25, 26] $[11,12]$. However, similarly to FGDPs, very few FDSs based their CRA on the use of a specific form_[12, 27-29][4, 13-15]. Despite the criticism about the lack of clear-cut validation of the proposed protocols/models, CRA forms are intended to help practitioners in managing a treatment plan strategy suitable for each patient $[25,30][11,16][25]$. CRA forms also allow a more objective and standardized collection of information, which could help gathering lots of epidemiological data in 
French hospital dental services, as it has been done at UCSF dental school for more than a decade [31, 32][17, 18]. Moreover, like FGDPs [12][4], FDSs consider current oral hygiene (87.4\%) and patient's motivation (45\%) as critical factors in a CRA for adult patients. Similar findings were reported in questionnaire studies among US and Japanese dentists $[29,33][15,19][28]$.

Like FGDPs, lack of time appears to be the most important factor identified among FDSs for not using CRA (FGPs: 67.2\%; FDSs: 67.7\%) [12][4]. However, it is surprising to note that 54.4\% also mentioned the lack of teaching and insufficient knowledge on CRA as reasons for not using CRA in everyday practice, knowing that CRA ishould be properly implemented in dental curriculum like suggested in the latest (at the time of the study) European curriculum recommendations in cariology [34, 35]._Most of respondents would appreciate a task delegation to other dental personnel like dental hygienists but unfortunately the profession of dental hygienists is still not recognised in France. Like FGDPs, some FDSs also denounce the problem of reimbursement (19.4\%) as barriers to the use of CRA at a regular basis $[11,12][3,4]$. Indeed, the Common Classification of Medical Acts (Classification Commune des Actes Médicaux or CCAM), which defines codification and billing of fees for procedures performed in dental practices in France, does not include a code for CRA while the national recommendations (HAS) encourage CRA in daily routine [20][36]. Regrettably, while the periodontal assessment has a classification code, the absence of CRA in the CCAM illustrates the lack of consideration of this critical step in the caries prevention, which should be a major public health concern.

DSs are part of the panel of primary and secondary prevention $[37,38][21,22]$; PDSs and TDSs are respectively indicated for caries initiation prevention in sound surfaces (ICDAS 0) in deep pits and fissures or for non-invasive management of non-cavitated carious lesions (ICDAS 1-3 and even ICDAS 1-4 for some authors). The state of evidences behind DSs is robust [39-44][23-28]. The present results show that almost all FDSs (96.6\%) declared placing PDSs at a regular preventive option. Nevertheless, only less than half of FDSs (44.3\%) considered TDSs placement. Similar findings were previously reported for GDPs practicing in France [11][3]. Indeed, while 90\% of FGDPs regularly perform PDSs, only $42 \%$ of them think about TDSs as preventive options. Lack of knowledge and risk of further lesion progression appear to be the most cited reasons (respectively $32.3 \%$ and 20.2\%) that explain the non-use of TDSs by the future practitioners studying in France. In contrast to the USA, where TDSs are part of the best practice recommendations, the HAS has not ruled on TDSs yet although it supports noninvasive strategies for non-cavitated carious lesions [37, 38][21, 22]. Unlike PDSs, there is no classification code in the CCAM for TDSs, which does not encourage GDPs to integrate these treatment options in their clinical practice. Instead, the lack of a classification code promotes the use of more invasive restorations for non-cavitated carious lesions, which are reimbursed by the French social security system and complementary health insurances.

Although three quarters of respondents stated that the undergraduate education related to CRA is sufficient, more than half of them reported some lacks towards both PDSs and TDSs. Worryingly, only $26.1 \%$ declared being familiar with the current national recommendations. In other countries, similar surveys administered to dental students and practitioners showed that respondents had a suitable theoretical knowledge about pit and fissure sealants; however, these studies also showed that there is a gap between their knowledge and the implementation of these preventive options in their clinical practices_[45, 46] $[29,30]$.

These results highlight several problems regarding particularly the undergraduate education stream of cariology, which appears to require further improvements. Similarly, continuing education, which has been introduced for several years in France, is mandatory for health professionals. As the subjects of training are not 
imposed and are selected by GDPs themselves depending on their preference, it is alarming to note that only $37 \%$ of them were interested in MI in 2015 [4][12]. Many reasons can explain this situation in Europe and especially in France. Changes in practitioners' attitudes about MI will only be achieved if clear information about the scientific rationale of CRA, the availability of easy-to-use CRA tools and evidence-based recommendations emerge $[31\}[47]$. Indeed, giving specific and simple guidelines to students and faculty members to accurately assign the caries risk levels for their patients could help them to improve CRA [48][32]. Admittedly, our study is a French example but there is little doubt that ithe same conclusions may be drawn in most of European countries: $\underline{\text { similar studies are thus needed to compare dental students' knowledge and npractices within countries and confirm }}$ this hypothesis.

Changing traditional practices into new concepts must involve common actions $[15,49][7,33]$. First of all, disparities concerning the teaching and practice of cariology that exist between French dental schools may lead to variations in FDS knowledge and treatment modalities. To address this problem, the college of teachers in conservative dentistry (CNEOC) could suggest concrete measures, for example writing a teachers' guide for dental curriculum, to standardize the education of MI in cariology in all French dental schools, according to the proposals of the European Core Curriculum for Cariology_[18, 34, 35, 50] $[9,34-36]$. Moreover, the objectives of the French (HAS) and European recommendations could also be redefined in order to favour evolutions of the health care system and reimbursement modalities (CCAM) towards an objective of caries prevention and to reconsider MI strategies as major public health concerns. 


\section{COMPLIANCE WITH ETHICAL STANDARDS}

\section{Conflict of Interest}

The authors declare that they have no conflict of interest.

\section{Funding}

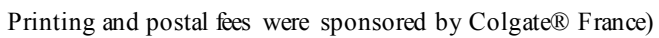

\section{Ethical approval}

All procedures fulfil French regulations related to questionnaire surveys in an educational environment.

\section{Informed consent}

Not applicable 


\section{REFERENCES}

1. Dawson AS, Makinson OF (1992) Dental treatment and dental health. Part 1. A review of studies in support of a philosophy of Minimum Intervention Dentistry. Aust Dent J 37:126-132.

2. Dawson AS, Makinson OF (1992) Dental treatment and dental health. Part 2. An alternative philosophy and some new treatment modalities in operative dentistry. Aust Dent J 37:205-210

3. Mount GJ, Hume WR (1998) A new cavity classification. Aust Dent J 43:153-159.

4. Mount GJ (2007) A new paradigm for operative dentistry. Aust Dent J 52:264-270.

5. Mount GJ, Ngo H (2000) Minimal intervention: advanced lesions. Quintessence Int 31:621-629.

6. Mount GJ, Ngo H (2000) Minimal intervention: early lesions. Quintessence Int 31:535-546.

7. Pitts N, Ismail AI, Martignon S, Ekstrand K, Douglas GV, Longbottom C (2004) ICCMS guide for practitioners and educators. https://www.iccms-web.com/uploads/asset/59284654c0a6f822230100.pdf Accessed April 9, 2020.

8. Martignon S, Pitts NB, Goffin G, Mazevet M, Douglas GVA, et al (2019) CariesCare practice guide: consensus on evidence into practice. Br Dent J 227:353-362.

9. Doméjean-Orliaguet S, Tubert-Jeannin S, Riordan PJ, Espelid I, Tveit AB (2004) French dentists' restorative treatment decisions. Oral Health Prev Dent 2:125-131.

10. Doméjean S, Maltrait M, Espelid I, Tveit A, Tubert-Jeannin S (2015) Changes in occlusal caries lesion management in France from 2002 to 2012 - a persistent gap between evidence and clinical practice. Caries Res 49:408-416.

11. Hélie B, Holmgren C, Gaillot L, Doméjean S (2016) Scellements préventifs et thérapeutiques Connaissances et pratiques des omnipraticiens français. Inf Dent 37:20-28.

12. Doméjean S, Léger S, Simon A, Boucharel N, Holmgren C (2017) Knowledge, opinions and practices of French general practitioners in the assessment of caries risk: results of a national survey. Clin Oral Investig 21:653-663.

13. Schwendicke F, Stangvaltaite L, Holmgren C, Maltz M, Finet M, et al (2017) Dentists' attitudes and behaviour regarding deep carious lesion management: a multi-national survey. Clin Oral Investig 21:191198.

14. Haugejorden O (1988) Adoption of fluoride-based caries preventive innovations in a public dental service. Community Dent Oral Epidemiol 16:5-10

15. Watt R, McGlone P, Evans D, Boulton S, Jacobs J, et al (2004) The facilitating factors and barriers influencing change in dental practice in a sample of English general dental practitioners. Br Dent $\mathrm{J}$ 197:485-489.

16. Schwendicke F, Doméjean S, Ricketts D, Peters M (2015) Managing caries: the need to close the gap between the evidence base and current practice. Br Dent J 219:433-438.

17. Tubert-Jeannin S, Doméjean-Orliaguet S, Riordan PJ, Espelid I, Tveit AB (2004) Restorative treatment strategies reported by French university teachers. J Dent Educ 68:1096-1103.

18. Schulte AG, Pitts NB, Huysmans MC, Splieth C, Buchalla W (2011) European Core Curriculum in Cariology for undergraduate dental students. Eur J Dent Educ 15 Suppl 1:9-17.

19. Loch C, Liaw Y, Metussin AP, Lynch CD, Wilson N, et al (2019) The teaching of posterior composites: A survey of dental schools in Oceania. J Dent 84:36-43.
Commenté [sd1 ]: 1.Meyer-Lueckel H, NJM, Breschi L, Buchalla W, Ceballos L, Doméjean S, et al (2019) EFCD Curriculumfor undergraduate students in Integ rated Conservative Oral Heal thcare (ConsCare). Clin Oral Inv estig 23:3661-3670. 
20. Kay EJ, Nuttall NM, Knill-Jones R (1992) Restorative treatment thresholds and agreement in treatment decision-making. Community Dent Oral Epidemiol 20:265-268.

21. Kay EJ, Nuttall NM (1994) Relationship between dentists' treatment attitudes and restorative decisions made on the basis of simulated bitewing radiographs. Community Dent Oral Epidemiol 22:71-74.

22. Mileman PA, Mulder E, van der Weele L (1992) Factors influencing the likelihood of successful decisions to treat dentin caries from bitewing radiographs. Community Dent Oral Epidemiol 20:175-180.

23. Mejare I, Sundberg H, Espelid I, Tveit B (1999) Caries assessment and restorative treatment thresholds reported by Swedish dentists. Acta Odontol Scand 57:149-154.

24. Tveit AB, Espelid I, Skodje F (1999) Restorative treatment decisions on approximal caries in Norway. Int Dent J 49:165-172.

25. Doméjean S, Banerjee A, Featherstone JDB (2017) Caries risk / susceptibility assessment: its value in minimum intervention oral healthcare. Br Dent J 223:191-197.

26. Fontana M, Gonzalez-Cabezas C (2019) Evidence-based dentistry caries risk assessment and disease management. Dent Clin North Am 63:119-128.

27. Riley JL, 3rd, Qvist V, Fellows JL, Rindal DB, Richman JS, et al (2010) Dentists' use of caries risk assessment in children: findings from the Dental Practice-Based Research Network. Gen Dent 58:230234.

28. Riley JL, 3rd, Gordan VV, Ajmo CT, Bockman H, Jackson MB, et al (2011) Dentists' use of caries risk assessment and individualized caries prevention for their adult patients: findings from The Dental Practice-Based Research Network. Community Dent Oral Epidemiol 39:564-573.

29. Riley JL, 3rd, Gordan VV, Ajmo CT, Bockman H, Jackson MB, et al (2015) Dentists' use of caries risk assessment and individualized caries prevention for their adult patients: Findings from The Dental Practice-Based Research Network. Tex Dent J 132:18-29.

30. Featherstone JD (2003) The caries balance: contributing factors and early detection. J Calif Dent Assoc 31:129-133.

31. Doméjean S, Featherstone JDB, White JM (2011) Validation of the CDA CAMBRA caries risk assessment - a six-year retrospective study. J Calif Dent Assoc 39:709-715.

32. Chaffee BW, Featherstone JD (2015) Long-term adoption of caries management by risk assessment among dental students in a university clinic. J Dent Educ 79:539-547.

33. Kakudate N, Sumida F, Matsumoto Y, Yokoyama Y, Riley JL, 3rd, et al (2015) Dentists' decisions to conduct caries risk assessment in a Dental Practice-Based Research Network. Community Dent Oral Epidemiol 43:128-134.

34. Bottenberg P, Ricketts DN, Van Loveren C, Rahiotis C, Schulte AG (2011) Decision-making and preventive non-surgical therapy in the context of a European Core Curriculum in Cariology. Eur J Dent Educ 15 Suppl 1:32-39.

35. Buchalla W, Wiegand A, Hall A (2011) Decision-making and treatment with respect to surgical intervention in the context of a European Core Curriculum in Cariology. Eur J Dent Educ 15 Suppl 1:4044.

36. HAS (2005) Appréciation du risque carieux et indications du scellement prophylactique des sillons des premières et deuxièmes molaires permanentes chez les sujets de moins de 18 ans. https://www.has- 
sante.fr/jcms/c_240379/fr/appreciation-du-risque-carieux-et-indications-du-scellem ent-prophylactiquedes-sillons-des-premieres-et-deuxiem es-molaires-perman entes-ch ez-les-sujets-de-moins-de-18-ans Accessed April 9, 2020.

37. Beauchamp J, Caufield PW, Crall JJ, Donly KJ, Feigal R, et al (2009) Evidence-based clinical recommendations for the use of pit-and-fissure sealants: a report of the American Dental Association Council on Scientific Affairs. Dent Clin North Am 53:131-147.

38. Beauchamp J, Caufield PW, Crall JJ, Donly K, Feigal R, et al (2008) Evidence-based clinical recommendations for the use of pit-and-fissure sealants: a report of the American Dental Association Council on Scientific Affairs. J Am Dent Assoc 139:257-268.

39. Borges BC, de Souza Borges J, Braz R, Montes MA, de Assuncao Pinheiro IV (2012) Arrest of noncavitated dentinal occlusal caries by sealing pits and fissures: a 36 -month, randomised controlled clinical trial. Int Dent J 62:251-255.

40. Wright JT, Tampi MP, Graham L, Estrich C, Crall JJ, et al (2016) Sealants for preventing and arresting pit-and-fissure occlusal caries in primary and permanent molars: A systematic review of randomized controlled trials-a report of the American Dental Association and the American Academy of Pediatric Dentistry. J Am Dent Assoc 147:631-645 e618.

41. Ahovuo-Saloranta A, Forss H, Walsh T, Nordblad A, Makela M, et al (2017) Pit and fissure sealants for preventing dental decay in permanent teeth. Cochrane Database Syst Rev 7:CD001830.

42. Frencken $\mathbf{J}$ (2019) Is preventing micro-cavities in dentine from progressing with a sealant successful? $\mathrm{Br}$ Dent J 226:590-594.

43. Hong M, Vuong C, Herzog K, Ng MW, Sulyanto R (2019) Sealed primary molars are less likely to develop caries. J Am Dent Assoc 150:641-648.

44. Munoz-Sandoval C, Gambetta-Tessini K, Giacaman RA (2019) Microcavitated (ICDAS 3) carious lesion arrest with resin or glass ionomer sealants in first permanent molars: A randomized controlled trial. J Dent 88:103163.

45. Ealla KKR, Kumar AN, Turagam N, Sooraparaju SG, Yerrapothu RMR, et al (2018)Knowledge analysis of pit and fissure sealants among the dental students of South India. J Int Soc Prev Community Dent $8: 508-512$.

46. Al-Maweri SA, Al-Jamaei AA, Halboub ES, Al-Soneidar WA, Tarakji B, et al (2016) Fissure sealants: Knowledge and practice of Yemeni dental practitioners. Eur J Dent 10:234-238.

47. Innes NP, Frencken JE, Schwendicke F (2016) Don't know, can't do, won't change: barriers to moving knowledge to action in managing the carious lesion. J Dent Res 95:485-486.

48. Young DA, Alvear Fa B, Rogers N, Rechmann P (2017) The effect of calibration on caries risk assessment performance by students and clinical faculty. J Dent Educ 81:667-674.

49. McGlone P, Watt R, Sheiham A (2001) Evidence-based dentistry: an overview of the challenges in changing professional practice. Br Dent J 190:636-639.

50. Meyer-Lueckel H, Opdam NJM, Breschi L, Buchalla W, Ceballos L, et al (2019) EFCD Curriculum for undergraduate students in Integrated Conservative Oral Healthcare (ConsCare). Clin Oral Investig $23: 3661-3670$. 